\title{
Measuring Causes: Episodes in the Quantitative Assessment of the Value of Money
}

Kevin D. Hoover and Michael E. Dowell

History of Political Economy

Annual Supplement to Volume 33 (2001) 371-374 


\title{
Measuring Causes: Episodes in the Quantitative Assessment of the Value of Money
}

\author{
Kevin D. Hoover and Michael E. Dowell
}

Historische Kaufkraftvergleiche schweben also immer mehr oder weniger in der Luft. —Wilhelm Röpke, Die Lehre von der Wirtschaft

\section{Money and Measurement}

Nothing is more familiar than the value of money. Every time we buy a book or a beer or note the price of a computer or a car, we simultaneously update our information about the value of money expressed in units of books, beer, computers, or cars. Money is nevertheless not like these physical goods. Value (or price) and quantity are separate characteristics for physical goods. A copy of Keynes's General Theory is the same book whether it costs $\$ 10$ or $\$ 10,000$. But a ten-dollar bill is, in a relevant sense, a different thing when a copy of the General Theory costs $\$ 10$ than when it costs $\$ 10,000$. That the real quantity of money depends on the prices of goods was understood well before the dawn of modern economics. It is sometimes not enough to evaluate that real quantity with respect to a book, a pint of beer, a computer, or a house. Both because it is a useful portmanteau statistic and because it plays a causal role in our theories of the macroeconomy, we sometimes need to know the real quantity of money with respect to goods in general - that is, we need to know the general price level. 
We are now so familiar with the idea of price indices that the idea of a general price level no longer appears problematic. But consider the recent discussion of the measurement of the Consumer Price Index (CPI), particularly in the wake of the December 1996 report of the Advisory Commission to Study the Consumer Price Index (commonly known as the Boskin Commission [Boskin et al. 1996]). Getting the right value for the price indices is important on several dimensions. There is a scientific interest in, for example, measuring the real Gross Domestic Product (GDP) or productivity growth. If the price indices are too high, we appear less prosperous and productive than we really are. Real GDP and productivity data, as well as inflation data that are based directly on the price indices, affect the policy actions of the central bank and so have important consequences for the future prosperity of the country. And they affect various index-linked payments in pensions and contracts, thereby affecting the distribution of income and government finance.

The Boskin report concluded that the CPI overstated inflation by 1.1 percentage points. While some commentators disputed the particular estimates, almost no one observed what a conceptually odd conclusion the report had drawn. Index numbers reduce the changes in prices of many goods to a single summary statistic. There is no unique, correct way to make that reduction. Although there are better and worse ways to make it, the class of theoretically admissible indices is infinite. To conclude that the CPI overstates true inflation by a precise amount is implicitly to claim that there is a precisely true price index, a unique value of money-but there is no such true index.

The problems of what the value of money is and how to measure it are not new. Both classical political economists and policymakers in the eighteenth and nineteenth centuries faced the same problems that we do today, albeit in an era much less rich in economic data and statistical understanding. They were perhaps less complacent about how to address the problems; for, although index numbers appeared during the same period, they had not yet come to dominate the thinking about the general price level. The goal of this essay is to look back to this earlier time and to a selection of classical authors to ask, What did they mean by the "value" of money? And how did they measure it?

There is, of course, a logically prior question that should be related to the conception of the problem at hand: what is measurement? We shall take measurement to mean the assignment of a quantitative value to a conceptually quantifiable variable, in our case the value of money, on 
the basis of empirical data. Assigning values to distance with a yardstick or to temperature with a thermometer epitomize measurement. In these cases, measurement consists of placing an instrument (the yardstick or the thermometer) in a physical relationship with the thing to be measured. For any interaction between the instrument and the thing to be measured to produce a useful result, we must maintain certain theoretical (and generally not directly testable) commitments. We assume, for instance, that the yardstick is rigid or that the mercury expands linearly. We must also assume that the system of measuring instrument and measured object are isolated in the sense that any interfering causes are trivial or have been shielded away or that we have a systematic method of compensating or accounting for their influences.

Although the same features of theoretical presuppositions and the need for isolation or compensation arise in economic measurement, there is rarely anything that corresponds to a tangible measuring instrument such as a yardstick or thermometer. Money and goods can be counted and prices recorded, but often these raw data are not the aspects of the economy that we seek to measure. Raw data are inputs to a process of manipulation in accordance with theoretical presuppositions-a process that assigns a number to a quantity that may not be directly observable to the senses, even in principle.

Indirect measurement is characteristic of many physical sciences as well as economics. Yet it raises the question of the difference between measurement and inference. The inferential distance between the thermometer and body temperature seems short compared to that between a spectroscopic photograph and the temperature of the sun or between a set of prices for thousands of goods and the value of money. Nevertheless we suggest the distinction between measurement and inference is heuristic rather than essential. We typically expect measurements to appeal to a different set of theoretical presuppositions than those at stake in the investigation at hand. If the linearity of the expansion of mercury with temperature was the question, we would not expect measurements made with a mercury thermometer to decide it. Related to this, we expect measurements to be transferable beyond the particular theoretical context in which they are made. Thus, we not only expect the fact that we measure the temperature of water to be $90^{\circ} \mathrm{C}$ to imply that an ice cube dropped into the water will melt, but also that we can calculate the rate at which it will melt based in part on transferring the measured temperature into the appropriate thermodynamical equations. Transferability is 
related to the notion that the measured variables are real characteristics. (See Spencer Banzhaf's essay in this volume for a discussion of conceptions of measurement and the value of money in the twentieth century.)

To address the question of measuring the value of money, we will examine some of the writings of Adam Smith, the Bullion Committee of 1810, Thomas Tooke, and William Stanley Jevons. Our purpose is limited. Each of the three individuals has written extensively on prices and money, and the Bullion Committee's report involved as authors and positive or negative critics many of the most important British economists of the day (e.g., David Ricardo). Our concern is neither with the totality of any of the author's works nor with the details of the monetary controversies in which they were involved except insofar as they directly affect our central purpose- understanding the motivations, problems, and pitfalls that each author faced in a particular empirical investigation aiming to quantify the value (or changes in value) of money. We also recognize that we may have been able to illustrate these issues with other authors or other works. We take an episodic rather than a systematic approach. For each author, taking the Bullion Committee as one, we examine a single text or part of a text, focusing on the concept of the value of money and the strategies used for measuring that value. Despite the episodic approach, there is nonetheless some continuity in the discussion. These authors can be read as carrying on a conversation. To one degree or another, the later authors comment on the earlier, and the problems that motivate each author's work are related to the those addressed by the earlier authors in a connected historical sequence.

\section{Adam Smith's "Digression Concerning the Variations in the Value of Silver"}

While Smith discusses his general notions of value and money in book 1 , chapters 4 and 5 of the Wealth of Nations, his attempt to quantify changes in the value of money does not occur until book 1, chapter 11, "Of the Rent of Land" in the "Digression Concerning the Variations in the Value of Silver" (Smith [1776] 1981, 195-259).1 The "Digression" sits in the midst of a discussion of the value of produce from land that always pays rent relative to land that sometimes does and sometimes does not pay rent. The general tendency, Smith argues, is for the produce of

\section{Page references are to the Glasgow edition of the Wealth of Nations.}


the land other than food to rise in value as the overall wealth of society rises. For goods that are not easily transportable (e.g., quarry stone), the relevant market is more or less local. But for silver, which is easily transported, the relevant market is the whole world. The value of silver in the world will depend on the proportion between supply, driven by accidental discoveries of new mines, and demand, driven by general economic development. Smith seeks to show that over four centuries the balance between supply and demand has shifted so that three distinct episodes can be discerned-each characterized by a particular general direction of the price of silver or, equivalently, the value of money.

The main purpose of Smith's investigation appears to be a detached scientific one: does the behavior of silver illustrate his understanding of the course of the value of nonagricultural produce over time? Smith ([1776] 1981, 200 and passim) also wishes to provide empirical evidence against the crudest version of the quantity theory of money. In the crude version, whenever the quantity of precious metals increases, so do prices. Smith objects that the stock of money naturally increases in a prosperous country, but that much of it is absorbed by the increased trade and the increased demand for silver and gold in luxury manufactures, so that prices need not increase. ${ }^{2}$ To make his case, he needs to measure the actual change in the value of silver.

Near the end of the "Digression," Smith ([1776] 1981, 258) goes on to suggest two further practical purposes for understanding the value of money: (1) to help judge accurately the state of the economy-prosperous or otherwise; and (2) to give information on cost-of-living adjustments for public servants (cf. Jevons 1863, 81-85; Cannan 1925, 67). (We presume that he exempts private employees on the ground that the market will set their wages appropriately.)

Conceptually, what is the value of money? is an easier question for Smith than for later authors. Since he holds a labor theory of value, the price of silver relative to labor is the true measure: "Labour, it must be remembered, and not any particular commodity or sett of commodities is the real measure of value both of silver and of all other commodities" ([1776] 1981, 206). This seems clear enough, but Smith is, in fact, not completely consistent, partly for reasons that are hard to fathom and

2. A similar position is taken by the Bullion Committee. See the disussion of the Bullion Committee Report below. 
partly for reasons that reflect theoretical presuppositions that guide his measurement strategy.

Immediately before the "Digression," Smith ([1776] 1981, 194) defines a fall in the value of silver as consisting in the fact that an amount of it would "purchase or command a smaller and a smaller quantity of labour, or exchange for a smaller and a smaller quantity of corn, the principal part of the subsistence of the labourer." Here corn appears to be as much a measure of the value of silver as labor itself, yet we know that labor is more fundamental than corn in Smith's account of value. In practice, Smith judges the value of silver from the silver price of corn. Why not collect wage rates rather than corn prices, as Tooke ([1838-57] 1972, 1: 55-56) would later argue would have been more consistent with Smith's analysis?3

The answer is not obvious, but we speculate on two considerations. First, Smith ([1776] 1981, 49, and book 1, chaps. 8 and 10) understands that labor and wages are heterogeneous across occupations. In contrast, what heterogeneity there is in corn is resolvable through straightforward, conventionally agreed upon adjustments. Second, Smith does not believe that the reward to labor measured in necessaries and luxuries is truly a constant (51). In his view wages are higher in an advancing state than in a declining state and may, in fact, fluctuate as well as trend. Thus, even if in some metaphysical sense labor is everywhere equally valuable, the question that forms the core of the Wealth of Nations-what makes a nation prosperous? - is a question about why some countries are rich in the necessaries and conveniences of life and others poor. Smith is shrewd enough to understand that knowing the labor value of silver (i.e., the nominal wage) without knowing about prices cannot answer that question.

Why then focus on corn and not "a sett of commodities"? It might seem that Smith has answered this question with the observation that corn is the largest part of the typical worker's subsistence. In fact, his answer is based more on his theory of how relative prices develop over time (Smith [1776] 1981, 206). He observes that the average supply and demand for any produced goods are on average nearly equal over long periods of time. Cattle are essential to corn production-both as a source of manure and as draft animals. Over time, technological improvements

3. References to Tooke's History of Prices ([1838-57] 1972) are by volume number and page number. 
raise corn production and tend ceteris paribus to reduce the price of corn. But rising productivity also raises the demand for cattle; the price of cattle increases as cattle production has to be moved off waste land onto arable land to meet this demand. Smith argues that the increased input price more or less offsets the productivity gain in corn production, rendering the price of corn in terms of labor nearly constant.

The question of changing relative prices arises again in Smith's discussion of cost-of-living adjustments for public servants. Here he notes that corn governs the profit rate in agriculture and that the price of other vegetable crops should fall on trend relative to corn while the price of butcher's meat rises ([1776] 1981, 258). Similarly, he expects to see falling real prices of manufactured goods (260-64). Thus for Smith, corn serves as an index - not in the modern sense of a weighted average, but rather in the sense of a neutral commodity that indicates where labor stands against commodities in general. Smith recognizes that the composition of the commodity bundle is likely to shift systematically over time with secular trends in relative prices.

The nature of the theoretical conception underlying Smith's advocacy of the corn price as the standard measurement of the value of silver points to the measurement of secular trends rather than year-to-year fluctuations. Smith ([1776] 1981, 228; 216) observes that the stock of precious metals is so large relative to the flow of new production that there is little year-to-year variation in supply. In contrast, the corn supply is highly variable from year to year. Corn is, therefore, a poor measure of short-run fluctuations in the value of silver or labor.

Smith's conceptual and theoretical framework is developed in passing as he encounters interpretive issues. In contrast, the bulk of the "Digression" is devoted to quantitative assessment of the changing value of silver. Smith seeks accurate data on corn prices. In the time before statistics were kept purposefully for economic analysis, this is no easy task. Smith puts together his raw data from a hodgepodge of sources: contemporary accounts in letters and other documents that record prices incidentally, old price-control statutes, contract prices, and the actual accounts of corn markets. Many of these data cannot be taken at face value but must be adjusted or interpreted. For example, Smith ([1776] 1981, 197) considers a price-control statute from 1262 in which the price of bread is tied to the market price of corn. He regards the middle price of the table as the normal price of corn on the assumption that the law treated probable price variations symmetrically. In another case, he observes that 
recorded conversion prices in cases in which landlords can take their rent in either money or corn are likely to be set at about half of the usual market price (200). Similarly, Smith must be careful to adjust weights and measures: reported corn prices must be adjusted for the relative proportions of wheat and barley (e.g., 210), while circulating silver coin must be adjusted for the degree to which it is degraded relative to standard coin (e.g., 212-13).

Collating and cleaning the data are only the start of the measurement process. The essential element is what we might today refer to as "signal extraction": how can the secular trend in corn prices be discerned in the pattern of year-to-year fluctuations? Smith observes that prices in unsystematic sources, such as letters or memoirs, are often extreme prices, since they were remarkable for their novelty. It would be wrong, he argues, to infer from the fact that the lowest prices in ancient times were much lower than the lowest prices today or from the fact that the highest prices in the thirteenth century were much higher than the highest prices today that in either case the normal prices were also much lower or higher ([1776] 1981, 203). ${ }^{4}$

Smith adopts two strategies for signal extraction. The first is timeseries averaging. For example, in the case of the earliest data (12231601), Smith ([1776] 1981, 268-71) reduces the raw data to twelve-year averages before drawing his conclusions about secular price movements. We can regard the averaging as an example of isolating the measuring apparatus from interfering causes through a strategy that renders these causes trivial, as discussed above.

The second strategy is to account for each of the interfering causes one by one in order to select only those corn prices that do not reflect special, transitory circumstances. Much of Smith's discussion of the data after 1570 employs this strategy. In the seventeenth century he appeals to circumstances such as the Civil War to account for the high price of corn in 1648 or the export bounty to account for the high price of corn in 1688 (Smith [1776] 1981, 212). An account of this sort, however, shifts the question somewhat, for Smith is no longer merely measuring the exchange value of corn. Rather, he is attempting to distinguish between changes in the exchange value that can be attributed to changes in silver and changes that can be attributed to some other cause. Both the shift

4. In modern terminology, the mean and the variance of prices are likely to show considerable independence. 
from measurement of the value of money simpliciter to measurement of the causes of changes in the value of money and Smith's strategy of attributing to changes in the supply of silver whatever changes in the value of money are left over once all other factors are accounted for recur in the other episodes that we shall consider presently. It is convenient to give Smith's strategy the anachronistic name "the method of residues" (see Mill 1851, 404). ${ }^{5}$

\section{The Report of the Bullion Committee of 1810}

By the time of the publication of the Bullion Report (Cannan 1925), Britain had moved from the silver standard, with which Smith is concerned, to a gold standard. In 1797 during one of the panics of the Napoleonic Wars, the Bank of England, at the direction of the government, suspended the convertibility of its notes (paper pounds sterling) into gold. This was intended as a strictly temporary measure but was in fact renewed successively until convertibility was finally resumed in 1821 . The Bullion Committee was a response to the inflation in the second half of the first decade of the nineteenth century. The committee's report sought to demonstrate that the cause of the inflation was the excess issue of Bank of England paper notes and to refute alternative theories of the inflation. Although the report was motivated by a general rise in prices, its terms of reference were limited to determining the cause of the high price of gold bullion. The main conclusion of the committee was that Britain should resume convertibility.

Unlike Smith, the Bullion Report is unburdened by any conceptual commitment to a deep account of value. The only value that explicitly concerns the committee is the exchange value of the paper pound in terms of gold or vice versa or indirectly with precious metals in other monetary systems through the foreign exchanges. There is no doubt that bullion prices in 1810 were substantially higher than the mint price of $£ 317 \mathrm{~s} .10 \frac{1}{2} \mathrm{~d}$. per ounce, mint price being that price at which the mint would convert gold bullion into legal tender coin. As a result, gold coin ceased to circulate, as it was completely supplanted by cheaper paper money. So far, no serious measurement issues arise. The deeper question,

5. The method of residues is described in Mill's $(1851,405)$ fourth canon: "Subduct from any phenomenon such part as is known by previous inductions to be the effect of certain antecedents, and the residue of the phenomenon is the effect of the remaining antecedents." 
however, was to what extent the rise in price of bullion was attributable to the policy of the Bank of England. The tricky problem is, then, one of measuring causes.

The alternative explanations for the high price of bullion focused on the disruptions to international trade and public finance as a result of the prolonged war with France. One argument was that the immediate need for gold to support the armies in the field had drained gold away from England, driving up its price. The committee rejects the conceptual basis for this argument (Cannan 1925, 10). 6 It admits that there is little gold in Britain but contends that gold cannot be considered scarce when as much can be had as desired for those willing to pay its high price. In effect the committee argues that goods are not scarce so long as their supply is infinitely elastic at their market price-a very modern conception of scarcity. And merchants assure the committee that gold is in fact freely available at the market price.

The committee is not, however, content with a conceptual argument. It seeks to measure the degree to which the rise in the price of bullion is attributable to the Bank of England. Its measurements are underpinned by a modified specie-flow mechanism.

The pure specie-flow mechanism (e.g., that attributed to David Hume) assumes that consumers seeking the cheapest goods send gold to countries with low prices and that the gold circulating as money drives up prices until the goods of the receiving (or home) country are no longer cheap relative to the sending (or foreign) country. The modified specieflow mechanism recognizes that the transport of gold is costly and that business between countries can be more effectively conducted through the exchange of merchants' bills drawn on the banks and denominated in the currencies of the different countries. The home country, with relatively cheap goods, then finds itself with an increasing stock of bills drawn on the foreign country. With an excess supply of such bills, their price falls, which is reported as a rise in the home country's (or a fall in the foreign country's) exchange rate.

Variation in the exchange rate is limited, however, since it can never diverge for long from the ratio of the gold content of the coin of the two countries adjusted for the cost of actually transporting the gold. The key idea is effective arbitrage. In this respect, the theory of the Bullion Committee resembles the modern corporate finance literature in that it

6. Page references are to Cannan's (1925) reprint of the committee's report. 
concerns end states rather than causal processes. In particular, the committee never attempts to provide any detail of the process through which excess Bank of England notes affect prices. Thus, while its theory is compatible with versions of the quantity theory of money, it is quite different from those versions, such as Milton Friedman's (a century and a half later), that attribute price increases to wealth effects and the consequences of portfolio rebalancing. The committee in fact rejects the notion that there is a fixed relationship between the quantity of money, the level of economic activity, and the price level such as might be reflected in a stable velocity of circulation. It states:

But the quantity of currency bears no fixed proportion to the quantity of commodities; and any inferences proceeding upon such a supposition would be entirely erroneous. The effective currency of the Country depends upon the quickness of circulation, and the number of exchanges performed in a given time, as well as upon its numerical amount; and all the circumstances which tend to quicken or retard the rate of circulation, render the same amount of currency more or less adequate to the wants of trade. (Cannan 1925, 57)

The committee's approach to measurement is straightforward and relies heavily on the modified specie-flow mechanism. With currencies convertible into gold, the price of gold should be the same everywhere and the currencies should trade at par-that is, in the ratio that reflects their relative gold content. With the pound sterling inconvertible, the committee assumes that since bullion remains available everywhere (this is the importance of their particular conceptualization of scarcity), the real price of bullion is the same everywhere and the real exchange rate is at par. Any excess of the nominal over the real price of bullion or any fall in the nominal exchange rate below par is, then, a direct measure of the effect of the excess paper pounds.

This measurement strategy is more difficult to implement in practice than the bare outline suggests. Unlike Smith, the Bullion Committee has relatively good data on exchange rates and gold prices themselves; the gold and foreign exchange dealers are a regular part of the merchant community and support circulars such as Lloyd's Lists and Wettenhall's Course of Exchange for business purposes (Cannan 1925, 8-9). Even with such data, there are at least two complications to consider. First, the par values for exchange rates are based on the assumption that coinage of the various countries is at its full legal weight. Actual deviations from 
par must account for the fact that coins of the various currencies may be clipped or worn to different degrees (Cannan 1925, 23-24). ${ }^{7}$ Second, the legal standard in some countries is gold and in other countries silver, requiring that calculations of par also account for the price of silver relative to gold.

More significantly, the Bullion Committee has a sophisticated understanding of the limits of its theoretical framework. Its strongest conclusions are delivered only under the assumptions that transport, handling, and conversion costs for bullion and coin are zero and that arbitrage is perfect and speedy. Most of the effort of measurement in its report is directed at setting bounds to these costs or limits to the effectiveness of arbitrage. The strategy is counterfactual. Supposing that there were no inconvertible paper money, how much could the price of bullion differ from the price of coin? And how much could the exchange rate vary from par?

The coinage of some countries-although not Great Britain-was subject to seigniorage. Loss to wear and tear for British coin is limited to 1.11 percent by legal tender statutes, although the committee estimates this loss to be less than 1 percent (Cannan 1925, 13-15). Legal restrictions on exporting gold derived from melting British coin-restrictions not easily enforced - add a premium of 3-4 shillings per ounce to bullion legal for export. Counting these and other costs, the committee estimates the largest difference possible between coin and bullion at 5 percent of the value of coin. It cites the experience in the years before 1797 as confirming that limit. ${ }^{8}$

Similarly, relying on the testimony of merchants, the committee recognizes that the cost of transporting bullion, including insurance, fluctuates with the military situation but does not exceed 7 percent (Cannan 1925, 25).

Some data are dismissed as outliers by appeal to violations of the ceteris paribus conditions of the modified specie-flow mechanism. For example, the military situation in Portugal resulted in a substantial balance of payments deficit with England and an exchange rate 131/2 percent in

7. Smith ([1776] 1981, 43-44) also addresses the "debased coin."

8. The committee did recognize one factor that would tend to cause the price of coin to rise above that of bullion. The opportunity cost measured as the lost interest for the period over which the bullion is being minted into coin is estimated at less than 1 percent. The committee also assumes this percentage is falling as the operation of coining bullion becomes more efficient (Cannan 1925, 12-14). 
favor of England. This situation is treated as anomalous. The excess demand for British bills had become so high and the exchange rate so favorable to England that the price differentials between England and Portugal had reached the point at which it was profitable to ship bullion. Equilibration through actual shipments of bullion is a slower process than equilibration through the trade in merchants' bills. And the market was too disordered to equilibrate in the usual manner as it would have in a politically and economically more stable situation.

Once all the factors by which the actual specie-flow mechanism in the real world differs from the ideal theory are taken into account, the measurement strategy of the committee is the same as that employed by Smith: whatever cannot be accounted for otherwise is attributed to the excess of paper money (the method of residues). The committee concludes that bullion is 15 to 16 percent above its mint price; at most, $5 \frac{1}{2}$ percentage points of that difference can be attributed to other causes than excess paper. The foreign exchanges stand 16 to 20 percent below par, and at most 7 percentage points can be attributed to the costs of actually shipping bullion. Between $91 / 2$ to 13 percentage points of the rise in the price of bullion is attributed to excess paper currency.

\section{Thomas Tooke's History of Prices}

The first volume of Tooke's monumental six-volume History of Prices was published in 1838-over a quarter century after the report of the Bullion Committee-and seventeen years after the resumption of convertibility. The first two volumes examined prices before and after the period of the paper pound. Tooke's aim was to bolster the case for the Banking School, which advocated that the currency be convertible and that banks freely discount "real bills" of good quality and short duration. The Banking School believed that paper money could not be inflationary in such an institutional environment. The last volume of the History (written with William Newmarch) was not published until 1857thirteen years after the Banking School was vanquished by the Bank Charter Act of 1844. This act institutionalized the operating procedures for the Bank of England, procedures advocated by its arch-rival, the Currency School. ${ }^{9}$ (See Thomas Humphrey's article in this volume for

9. The Bank Charter Act divided the Bank of England into an issue department and a banking department. The issue department was required to fully back any notes in excess of $£ 14$ million with bullion or coin (Andréadès [1909] 1966, 289). 
a discussion of the role of the Federal Reserve's allegiance to the real bills doctrine in its choice of what to measure in the 1910s to 1930s.)

The scope of Tooke's investigations into the value of money rivals that of Smith, and his attention to factual detail considerably exceeds Smith's. Yet his purposes are less detached: Tooke sought to refute the empirical basis for one set of monetary policies and to establish that of another. His concern for topical problems in monetary policy helps to explain his short-run focus. ${ }^{10}$ Smith identified trends; Tooke hopes to explain year-to-year variation. His is not a descriptive task but one of causal assignment. The question is "Whether, in the altered proportions between money and the objects exchanged by it, the variations of prices, consequent on those altered proportions, originated in, and were dependant upon, alterations in the quantity of money on the one hand, or in the cost of production, and the accidents affecting supply, on the other" (Tooke [1838-57] 1972, 1:154; emphasis in original).

That the requisite measurements aim to establish causes, not merely to describe relative prices, is central to Tooke's enterprise. He draws a distinction between the "depreciation of currency," which he defines as the mismatch between the actual metallic content of coin and the mint regulations or between paper money and the coin that it is supposed to represent, and the "depreciation of money," which he defines as a fall in value of money owing to an increase in its quantity "indicated by, and commensurate with, a general rise in prices of commodities and labor" (Tooke [1838-57] 1972, 1:119-23). The Bullion Committee addressed the depreciation of the currency, but Tooke believes that the relevant question for his time is the depreciation of money.

Unlike Smith or the Bullion Committee, Tooke's conception of the value of money is fuzzy in its essence: 11

Of variations in the value of the standard itself there is no infallible criterion. Variations, therefore, in the value of the standard, if they occur, can only be inferred from variations of considerable extent and duration, in the bullion prices of commodities and labour, in cases in which these variations do not, according to the widest induction of facts, admit of being accounted for, by circumstances which have influenced

10. Tooke does not deny that there are secular trends in prices; it is just that they are not what interests him in the context of monetary policy.

11. Although Tooks's conception of the value of money was "fuzzy," it is again an application of the method of residues. 
the prices of the commodities and labour in question, independently of the supposition of any alteration in the quantity or rate of circulation of the currency. ([1838-57] 1972, 1:125)12

Tooke brings a wide range of information to bear on the question of the changing value of money, but it remains unclear what process he uses to aggregate it and draw firm conclusions. There may be some element of truth in the view (which might be taken by any modern-day economist) that Tooke was simply a fact grubber who has outrun the resources of his statistical methods. Yet, this is not the whole story.

Tooke was aware of the existence of index numbers. He cites, for instance, Arthur Young's crude cost-of-living index (Tooke [1838-57] 1972, 1:226n). Despite his familiarity with the idea, price indices play no part in the History of Prices. A price index would not in any case have necessarily captured Tooke's conception of the general price level. He states his conception directly: "It is the quantity of money constituting the revenues of the different orders of the state, under the head of rents, profits, salaries, and wages, destined for current expenditure, according to the wants and habits of the several classes, that alone forms the limiting principle of the aggregate of money prices, - - the only prices that can properly come under the designation of general prices" ([183857] 1972, 3:276). Tooke's conception is rather closer to the current one of national income or to John Maynard Keynes's "aggregate demand price" than it is to the CPI or other index number for prices.

Tooke's conception of general prices is well suited to the theoretical presuppositions on which his measurement strategy is based. The first two volumes of the History aim to refute the view of the Currency School that the decline in prices from the resumption of convertibility in 1821 up to the time Tooke is writing was the result of a reduction in Bank of England paper notes. The Currency School was regarded as the intellectual successor to the Bullion Committee. So it is surprising that Tooke ([1838-57] 1972, 1:4, 123-7) fully supports the analysis, the measurements of depreciation, and the policy conclusions of the Bullion Committee as well as Ricardo and other "bullionists." His objection to the Currency School is, as he characterizes it in his Inquiry into the Currency Principle ([1844] 1959, 6), that it adopts a crude version of the specie-flow mechanism, in which prices are determined by gold flows

12. Tooke's reference to "variations of considerable extent and duration" should not be taken in context to imply a focus on secular changes in prices. 
and all gold is treated as if it were coin and, therefore, part of the circulating medium, without any account of the mechanisms through which such flows might affect demand or the costs of production. What is more, Tooke ([1844] 1959, 67-73) charges the Currency School with arbitrarily treating Bank of England notes as a perfect substitute for coin, irrespective of whether they are convertible or not, and unaccountably distinguishing between these notes and other financial assets used in trade, including merchants' bills and country banknotes. The Bullion Committee was no more specific in its description of the mechanism of price change than the Currency School, but its adherence to the modified specie-flow mechanism in which actual gold flows are secondary and its agnosticism with respect to the proportionality of prices to money are more consonant with Tooke's own views.

Tooke's main theoretical objection to the Currency School can be cast positively as the key to his own approach. In his definition of general prices cited above, as well as in the practical judgments he makes throughout the History, it is clear that Tooke believes that, when examined from the point of view of causal processes, money is never the proximate cause of price changes. At best, money affects prices indirectly through incomes and expenditure and, therefore, through demand or interest rates (which he regards as part of the cost of production and supply, though only in the long run) ([1844] 1959, 69-72, 81; [1838-57] 1972, 1:115, 2:347, 5:583-4).

Tooke's approach is fine-grained and critical. He tries to show that his opponents' theories are inconsistent with the data examined broadly. For example, relying on the idea that increases in the money stock should scale prices generally upward, Tooke (e.g., [1838-57] 1972, 1:232) offers evidence that some prices rise and others fall. At a minimum, he makes the point that price change is unlikely to be monocasual, that it is net effects that are observed, and that some decomposition is necessary (e.g., 1:124-5). In this and other respects, his approach is similar to Smith's; yet Tooke criticizes in detail Smith's empirical account of the progress of the value of silver. He questions, for instance, Smith's adjustments to the quantity data on corn, which were meant to account for its variable quality (Tooke [1838-57] 1972, 1:23). More importantly, he criticizes Smith's measuring strategy. He argues that Smith is inconsistent in defining value in terms of labor and then declining to use the money wage as data on the changing value of silver: the money price of "common day labour" is, Tooke (1:56) writes, "a better criterion than 
corn, of the value of the precious metals." And he goes on to point out that laborers consume many other commodities than corn. As we have already observed, Smith's justification for focusing on corn prices was more subtle than simply that corn forms the largest portion of a worker's subsistence. So, to some extent, Tooke misses Smith's point.

More tellingly, Tooke criticizes Smith's strategy of isolating changes in corn prices resulting from changes in the value of silver from those resulting from supply conditions in agriculture. Smith averaged his data into twelve-year blocks, hoping to cancel out year-to-year fluctuations. Tooke ([1838-57] 1972, 1:59 and passim) demonstrates through a yearby-year analysis that the seasons show long cycles of successive good and bad years. ${ }^{13}$

The measurement strategy, which Tooke also employs for later periods, is exemplified in his reanalysis of Smith's account of the seventeenth and eighteenth centuries. Tooke examines each price change and attempts to give an adequate explanation in nonmonetary terms. Only the unexplained residual can be attributed to monetary factors-the method of residues again, and applied relentlessly.

It is surprising, and apparently inconsistent, given Tooke's criticism of Smith's focus on corn, that Tooke himself mainly cites corn prices. In the early volumes of the History, wage rates and the prices of other commodities are sometimes mentioned, but only corn prices are examined systematically. In the later volumes, other prices are cited more frequently, but corn dominates. Tooke ([1838-57] 1972, 1:5-6) identifies the sources of price changes as (1) the seasons, (2) the vicissitudes of war, (3) monetary conditions, (4) changing population, and (5) technical progress. The last two he dismisses as operating too slowly to be important for the short-term changes in the value of money that interest him. In this conclusion, he clearly demonstrates how his purposes are different from Smith's.

Appealing to Charles Davenant's empirical law, which shows that the price of corn is highly sensitive to small variations in the size of the harvest, Tooke ([1838-57] 1972, 1:10-12) places the greatest explanatory weight on the seasons - that is, on changing supply conditions. ${ }^{14}$ While he sometimes cites data on the stocks of wheat and other grains, he

13. In the language of modern time-series analysis, Tooke shows that that there is a near unit root in the seasons, so that reversion to the mean is a slow process for which twelve-year averages are too short.

14. See the article on Davenant in Palgrave's Dictionary (1925). 
appears to lack any systematic source of information on quantities of grain. The appeal to Davenant's law is more an argument for the plausibility of large price swings than the basis for measurement. Indeed, though Tooke acknowledges the need to compose causes in order to compute the net effects on prices, he provides no basis for quantitatively implementing such a composition. He writes as if it is enough to show that when prices are abnormally high, the harvest was abnormally low, to demonstrate that any monetary explanation is unnecessary for any part of the price change.

A similar lack of a technique for quantitative assessment plagues Tooke's appeal to the data on price changes for a wider spectrum of goods. At best he is able to point out instances when goods typically do or do not rise and fall in price together. He does draw quantitative conclusions, but the technique is opaque. For example, at one point he cites his own testimony to Parliament on the fall of prices for forty nonagricultural commodities, which he estimates to be 40 percent ([183857] 1972, 2:88). The reader is left to puzzle where the number might have come from. Arnon $(1990,17)$ characterizes Tooke as a sort of idiot savant (our words, not Arnon's) who, deeply immersed in the data, was able to draw conclusions about the general direction of pricesconclusions that a modern statistician would have drawn using index numbers. Tooke had argued, for example, that prices in 1810 and 1811 had fallen, whereas the bullionists had argued that they had risen. Arnon's index numbers support Tooke.

Tooke's failure to provide aggregate measures of changing prices is, as we have already argued, at least in part justified by his own conception of the value of money. The interaction of his strategy of treating each price change as sui generis with his theoretical presupposition that money affects prices only indirectly is nearly self-validating for his view that monetary conditions in fact affected prices very little. He was, as we have noted already, willing to agree with the Bullion Committee that the inflation in the second half of the first decade of the nineteenth century was the result of an excess issue of inconvertible paper. Symmetrically, he was willing to concede that part of the price fall after the resumption of convertibility in 1821 could also be attributed to the change in monetary regime-but no more than to the degree of divergence in value between paper and gold (that is, about 6-7 percent in his estimation). Other than that case, with no technique of decomposing price changes, Tooke is content to show that any time prices change, there is some nonmonetary 
factor operating in the right direction. It is hard to see that any residue could be left for which monetary explanation would be requisite.

\section{William Stanley Jevons's “A Serious Fall in the Value of Gold"}

Although William Stanley Jevons's "A Serious Fall in the Value of Gold" (1863) was written only a few years after the final volume of Tooke's History, it belongs to a different intellectual world. The great monetarypolicy debates of the first half of the nineteenth century had been resolved in practical political terms in favor of the Currency School. Jevons's concerns are, in many ways, closer to Smith's than to the Bullion Committee's or Tooke's. The operation of the banking system and the problems of paper currencies are hardly mentioned. The focus is on the metallic standard. New supplies of gold had been discovered in California and Australia. Jevons's question was to what degree these affected the value of money. Although he was not concerned with the course of the value of money over centuries as Smith had been, he was, in contrast to Tooke and the Bullion Committee, concerned with the permanent changes - secular rather than cyclical (to use a modern terminology that Jevons would have appreciated).

Jevons's conception of the value of money is strictly exchange value: "All that is meant by a fall in the value of gold, is the fact that more gold is now usually required to purchase an article than in former years" $(1863,18)$. Like Tooke, Jevons was aware of the essential ambiguity of this definition: "Value is a vague expression for potency in purchasing other commodities" (20). If gold becomes less potent in its ability to purchase some commodities and not more potent with respect to others, then its value has certainly declined. The standard (to use later terminology) is Pareto dominance. But given that Pareto dominance is rarely exemplified in the economy, Jevons strikes a pragmatic pose: if the increases in prices of goods predominate over the declines, then the value of gold is said to fall. Anticipating the results of his investigations, he writes: "I regard the fall in the value of gold as conclusively proved, although the exact nature of the problem is left amid the obscurities of economic science in general" (21). Jevons is thoroughly modern in his desire to provide a precise numerical answer to an intrinsically vague question.

Jevons's theoretical presuppositions are partly statistical and partly economic. On the statistical side he begins with the notion, vaguely 
justified by appeals to probability, that a price rise is more likely to occur as the result of a change in the quantity of gold if the prices of many goods rise relative to gold rather than the price of just one. The idea is that the supply conditions of the various goods are independent, so that in any reasonable aggregation they should cancel out, where the supply conditions of gold affect the price of all goods relative to gold and so will not cancel out. ${ }^{15}$ (For a more detailed discussion of this point, see Harro Maas's essay in this volume.)

Like Smith and Tooke, Jevons acknowledges that prices will be affected by changing conditions of supply and demand for each good. Since he wishes to determine the permanent component of price change caused by changes in the stock of gold, he must eliminate the effects of cyclical variation. ${ }^{16}$ In contrast with the earlier authors, Jevons is keenly aware of the trade cycle. He argues that ideally one would like to compare prices at the same relative point across different trade cycles. Practically, however, he recognizes that cycles have different lengths, so that it is generally impossible to locate the precisely analogous point in different cycles $(1863,34-35)$. Instead, he suggests comparing the averages across cycles. In this approach, he appeals to the same notion of cancellation of transitory influences through time that we argue motivated Smith to look at twelve-year averages. But Smith's averages covered periods with arbitrary end points, whereas Jevons needs to date the beginnings and ends of the particular cycles. He does this by looking at the time series for interest rates, appealing to his own theory of how interest rates vary with the trade cycle (36).

Jevons's strategy for measurement is to exploit the independence of transitory variation both across commodities and over time. He constructs index numbers. Index numbers are not original to Jevons; his novelty lies in applying them to the problem of the value of money. ${ }^{17}$ His

15. Jevons $(1867,153)$ further clarifies the point, arguing that given the complexities of the measurement problem "we can only attack them by the use of averages, and by so trusting to probabilities." With fifty commodities, "the probability is almost infinite" that individual causes will cancel.

16. "At the same time, we shall be put on our guard against mistaking any temporary fluctuation due to excessive investment or credit, for the effect of gold depreciation. . . . To eliminate such disturbances in our comparisons of prices before and after the gold discoveries, we might compare the prices at corresponding points of the commercial tide" (Jevons 1865, 34).

17. In another article, Jevons $(1865,119-20)$ suggests that index numbers would have helped Tooke and William Newmarch to reduce and render more interpretable the mass of price data in the History. As we noted above, Tooke knew about index numbers in a general way. Jevons's first reference is to a tabular standard of value due to Evelyn in 1798. Chance 
index numbers are simple geometric averages of the prices of a selection of thirty-nine major (and, subsequently, of an additional seventy-nine minor) commodities $(1863,38-41,51)$. (For a more detailed account of Jevons's methodology in constructing his index numbers, see Sandra Peart's article in this volume. For a discussion of his choice of the geometric mean, see Maas this volume.) Jevon's data is mainly drawn from The Economist. He is aware of many of the issues regarding the appropriate methods of weighting different prices familiar in modern treatments of index numbers $(1863,21)$. But Jevons lacks information on the quantities of commodities. He argues that his separate examination of major and minor commodities amounts to a demonstration that his main conclusions are insensitive to weightings (57). Using these indices, Jevons is able to compare price changes between cycles for the period before the discovery of gold in California through 1862 . He concludes that prices in general have risen 9 to 15 percent over that period and that this price rise could be caused only by changes in the stock of gold.18 (See Peart this volume for a discussion of the reactions to Jevons's conclusions.)

Like the earlier authors, Jevons adopts strategies of isolation and compensation. The cross-sectional averaging process implicit in the construction of his index numbers is one such strategy, as is the use of business cycle averages of the index numbers themselves. He also makes adjustments to the data-for example, to cotton prices affected by the American Civil War - to account for special circumstances unrelated to gold (1863, 26-27).

The assumption of independence is crucial if his averages are to eliminate disturbing influences. And while Jevons investigates possible lack of independence among the minor commodities, noting for instance that bar iron, pig iron, and tinned iron plates, which appear as individual commodities are effectively a single commodity $(1863,54)$, he never offers any detailed support for the notion that the only source of interdependent price movement must come from changes in the gold supply. ${ }^{19}$ In particular, he does not confront the possibility raised by Smith

(1966) finds the earliest example of an index number in 1675. While Smith did not use index numbers himself, much of his data is drawn from William Fleetwood, whom Chance (109) credits with having been aware of all the elements of index numbers.

18. The range of estimates corresponds to the range of price indices that he computes.

19. Jevons also believes that technological progress can affect the value of gold independently of the supply of gold, but he expects the effects to act too slowly to interfere with his measurements over the chosen time horizon. 
that secular changes in relative prices might undermine the ability of the index numbers to extract the monetary signal from the economic noise. 20 It may be true that as matters of pure data processing, Jevons's index numbers are, as he writes, "independent of any assumptions as to the cause of the fall in the value of gold" (58-59). Nevertheless, his choice of how to construct them and how to manipulate them is guided by his theoretical assumptions and his ultimate purpose of identifying the cause of the decline of the value of gold with its changing supply.

In constructing his index numbers Jevons, like the previous authors, employs the method of residues. Because it differs from modern practice, it is easy to misunderstand Jevons's approach and to regard it as positively characterizing changes in the value of money rather than subtracting away nonmonetary influences. Unlike modern economists, Jevons does not argue that his index number captures the change in the value of money in a neutral way that could be used as an input into a study of the causes of that change. Rather he claims that, in the very construction of the index number itself, the nonmonetary causes have cancelled out. The index number is itself a residue-whatever would not cancel—and is a measure of the monetary causes of changing prices.

Both Tooke and Jevons appeal to the method of residues. Given Tooke's theoretical assumptions, the method of residues all but guarantees that little of the change in prices will be attributed to money. Jevons seems to speak directly to Tooke's measurement strategy when he writes:

It may seem to some persons that the best and perhaps only way to ascertain whether and why prices have altered, is to examine the circumstances of the demand and supply of each article. I do not hesitate to say that the whole inquiry would be thrown into confusion by any such attempt, and that for the particular purposes of our inquiry it is better not to know the details concerning the articles. If you are able to explain the rise or fall of one commodity by circumstances unconnected with gold, and throw it out of the inquiry, you must do the same with others, or else the impartial balance of the inquiry is overthrown.... A searching inquiry into the conditions of supply and demand of every article would result in every one being thrown out as

20. He offers a decomposition of price changes into a trend and an idiosyncratic relative price component that depends on mean reversion in the relative price component. The necessary mean reversion is an untestable identifying assumption. 
unworthy of reliance as a measure of the value of gold. $(1863,58)^{21}$

Jevons's conclusion, although it is antithetical to Tooke's, bears the same self-validating quality: best to leave some proportion of the change in prices unexplained, for that proportion is what is attributable to gold, and otherwise nothing would be attributed to gold.

\section{Measuring the Value of Money in Historical Context}

It should come as no surprise that we found that the measurement strategies of each of the authors reviewed are imbued with theoretical presuppositions and are shaped by the author's particular conception of the value of money. This conclusion is inevitable because it reflects our own methodological presupposition. Although it was not obvious beforehand, rereading the four authors with the question "How did they try to measure?" squarely in mind made us realize just how different their investigative aims and conceptions of the value of money are. To some extent this was not obvious to the authors themselves. Tooke seems to talk past Smith in his detailed criticism of Smith's measurements. He betrays little recognition of how much Smith was concerned with secular rather than short-run change and with a desire to address the causes of prosperity rather than just the causes of price change.

A focus on causes is common to all the authors. One might think that there is a neutral description of the changes in the value of money on which all could agree as a preliminary to debating the causes. Both Jevons and Tooke are explicit in claiming that this is so. But the practice of all the authors belies their protestations: each has devised a measuring strategy that aims to reveal the quantitative significance of particular causes of changing prices. Both Tooke's and Jevons's measurement strategies very nearly build their qualitative-if not quantitative-conclusions into their measuring systems.

A final point, not obvious at the beginning, is that all the authors identify the monetary causes of price change through the method of residues: whatever is left after all the other factors are accounted for must be attributable to money. Why measure negatively? We end with a conjectured answer. The very notion of the general value of money is a fuzzy one. It

21. This view is contradicted by Jevons himself when he adjusts the data for the effects of the American Civil War on cotton prices. It appears Jevons is willing to throw out some observations. 
is hard to be precise about what it is conceptually. Therefore it is equally hard to know what in the world to measure that might correspond to it. But it is feasible to measure some things in the world that it is not. Whatever is left must include the value of money.

\section{References}

Andréadès, A. [1909] 1966. History of the Bank of England: 1640 to 1903. 4th ed. New York: Kelley.

Arnon, Arie. 1990. What Thomas Tooke (and Ricardo) Could Have Known Had They Constructed Price Indices. In Perspectives on the History of Economic Thought. Vol. 4, Keynes, Macroeconomics and Method. Edited by D. E. Moggridge. Brookfield, Vt.: Edward Elgar.

Boskin, Michael, et al. (Boskin Commission). 1996. Toward a More Accurate Measure of the Cost of Living: Final Report to the Senate Finance Committee from the Advisory Commission to Study the Consumer Price Index. Washington, D.C.: U.S. Congress.

Cannan, Edwin. 1925. The Paper Pound of 1797-1821: A Reprint of the Bullion Report. 2d ed. London: P.S. King \& Son.

Chance, W. A. 1966. A Note on the Origin of Index Numbers. The Review of Economics and Statistics 48.1:108-110.

1996. Some Suggestions for Complicating the Theory of Money. In Interactions in Political Economy: Malvern after Ten Years, edited by Steven Pressman. London: Routledge.

Jevons, William Stanley. 1863. A Serious Fall in the Value of Gold Ascertained, and Its Social Effects Set Forth. In Investigations in Currency and Finance, 13-118. New York: Kelley.

- 1865. The Variation of Prices and the Value of Currency Since 1782. In Investigations in Currency and Finance, 119-50. New York: Kelley.

. 1867. The Depreciation of Gold. In Investigations in Currency and Finance, 150-59. New York: Kelley.

. [1884] 1964. Investigations in Currency and Finance. New York: Kelley.

Mill, John Stuart. 1851. A System of Logic, Ratiocinative and Deductive: Being a Connected View of the Principles of Evidence and the Methods of Scientific Investigation. 3d ed. Vol. 1. London: John W. Parker.

Davenant, Charles R. 1925. In Palgrave's Dictionary of Political Economy, edited by Henry Huggs, C. B. Inglis and R. H. Inglis, 483-85. London: Macmillan.

Smith, Adam. [1776] 1981. An Inquiry into the Causes and Consequences of the Wealth of Nations. Glasgow ed. Edited by R. H. Campbell and A. S. Skinner. Indianapolis, Ind.: Liberty Fund. 
Tooke, Thomas. [1838-57] 1972. A History of Prices and the State of the Circulation from 1793 to 1837. 5 vols. New York: Johnson Reprint Corporation.

. [1844] 1959. An Inquiry into the Currency Principle: The Connection of the Currency with Prices and the Expediency of a Separation of the Issue from Banking. London: London School of Economics and Political Science (University of London). 